\title{
EXPANSIÓN ULTRAMARINA, LITERATURA DE VIAJE Y REPRESENTACIÓN DEL OTRO EN LA HISTOIRE D'UN VOYAGE FAIT AUX ILLES MALOUINES (1770) DE JOSEPH ANTOINE PERNETY
}

\author{
OVERSEAS EXPANSION, TRAVEL NARRATIVES AND THE REPRESENTATION \\ OF OTHERNESS IN JOSEPH ANTOINE PERNETY'S HISTOIRE D'UN VOYAGE \\ FAIT AUX ÎLES MALOUINES (1770)
}

\author{
Carolina Martínez*
}

\begin{abstract}
El presente artículo tiene por objetivo analizar el papel del relato de viaje como constructor y reproductor de subjetividades en el proceso de expansión ultramarina que Europa inicia en la modernidad temprana. Para ello se parte de la premisa de que entre los siglos XVI y XVIII el relato de viaje se volvió un recurso eficaz para dar cuenta de nuevos tipos de alteridad al tiempo que, haciéndose eco de otras formas de representación como mapas y relaciones, contribuyó a delimitar el espacio americano en términos geográficos, políticos y culturales. A partir del análisis del viaje a las islas Malvinas (1763-1764) y de la consecuente publicación de la Histoire d'un voyage aux Îles Malouines (1770) del fraile benedictino Joseph Antoine Pernety, el trabajo se propone entonces recuperar la dimensión cultural de la colonización en América, haciendo particular hincapié en su vínculo con las ambiciones expansionistas de Francia y el desempeño de esta potencia en el concierto de rivalidades concitadas por la carrera ultramarina.

Palabras claves: Relatos de viaje, expansión ultramarina, Francia, alteridad americana.
\end{abstract}

The purpose of this article is to analyze the role played by travel narratives in the construction and reproduction of subjectivities throughout the process of overseas expansion led by Europe in the Early Modern Age. Between the $16^{\text {th }}$ and $18^{\text {th }}$ Centuries travel writing became an efficient instrument to account for new kinds of others, thus contributing to "construct" America in geographical, political and cultural terms. Considering the analysis of French Benedictine Joseph Antoine Pernety's journey to the Malvinas Islands (1763-1764), and his subsequent travel account (Histoire d'un voyage aux Iles Malouines, 1770), the objective of this article is to highlight the cultural dimension of American colonization by making special emphasis on the influence of French expansionist ambitions and its place in the race for new overseas territories.

Key words: Travel narratives, overseas expansion, France, American otherness.

\section{Introducción: el relato de viaje como constructor de nuevas identidades}

Los relatos que se editan y circulan a partir de una experiencia de viaje operan, en más de un sentido, como mecanismos de traducción de aquellas nuevas culturas y espacios geográficos que solo se vuelven asibles al lector en la medida en que existe entre este y el viajero-testigo ese "saber compartido" definido por François Hartog en su estudio acerca de los escitas (Hartog 2002). Ahora bien, ese proceso de construcción del otro, que Michel de Certeau ubica en el trayecto de ida y vuelta que implica todo viaje y que se manifiesta también en su respectivo relato ${ }^{1}$, resulta no solamente uno de los rasgos más sobresalientes del relato de viaje en sentido amplio, sino ante todo del relato de viaje producto de la llamada modernidad temprana.

En efecto, en el proceso de expansión ultramarina que Europa inicia a fines del siglo XV el relato de viaje se volvió un recurso eficaz para dar cuenta de nuevos tipos de alteridad al tiempo que, haciéndose eco de otras formas de representación como mapas y relaciones, contribuyó a delimitar el espacio americano en términos geográficos, políticos y culturales. Podría decirse entonces que las primeras impresiones de aquel encuentro de mundos que se inicia con los primeros viajes de descubrimiento, y que para autores como Anthony Pagden son prueba irrefutable del nacimiento de una era moderna ${ }^{2}$, encontraron en el relato de viaje el medio a partir del cual expresarse. De tal

\footnotetext{
* Universidad de Buenos Aires, Facultad de Filosofía y Letras. CONICET. Museo Etnográfico Juan B. Ambrosetti. Buenos Aires, Argentina. Correo electrónico: cmartinez79@gmail.com
} 
forma, entre los siglos XVI y XVIII, características del relato de viaje en términos generales como el asombro, la maravilla o las expectativas frente al otro posibilitaron la reflexión y la comparación respecto de costumbres y creencias propias y ajenas (Hartog 2002: 205).

Ahora bien, más allá de que para François Hartog sea esta la característica esencial de todo relato de viaje, la diferencia que comportaron los relatos de viaje producidos a partir de las primeras experiencias en el Nuevo Mundo radicó en el hecho de que, tal como ha señalado Michel de Certeau, en la modernidad temprana la escritura y la palabra adoptaron nuevas funciones (De Certeau 1975: 247). A su vez, en términos del historiador norteamericano Stuart Schwartz, la experiencia del viaje en América y las producciones literarias que de ella surgieron implicaron la modificación constante de aquella primera impresión o visión del otro producto del inicial encuentro de mundos. En otras palabras, las representaciones que Europa realizó de los mundos y sociedades no europeos constituyó un proceso dinámico en el que las mismas fueron constantemente modificadas tanto por los contextos de producción como por los objetivos y las percepciones de los actores en juego.

Schwartz (1994) plantea que, entre los siglos XVI y XVIII, el encuentro entre europeos y no europeos no debería ser concebido entonces como el resultado de la simple correspondencia entre aquello que se esperaba hallar y aquello que efectivamente se halló. Antes bien, muchas de las concepciones y expectativas previas debieron reajustarse e incluso descartarse frente a un conjunto de experiencias y encuentros inéditos. En lo que refiere a este último punto, el historiador norteamericano hace particular hincapié en la "tensión dinámica" (Schwartz 1994) existente en el complejo encuentro entre mundos, matizando de tal forma la idea de una transferencia sin equívocos presentada hace ya algunos años por Tzvetan Torodov. En sus términos:

...el proceso fue complicado e inestable. Cualquiera hayan sido los entendimientos y expectativas previas, más allá de lo generalizado que haya estado el entendimiento de 'otros', los contactos en sí causaban reajustes y reevaluaciones en la medida en que cada bando era forzado a reformular sus ideas sobre sí mismo y sobre el otro en vista de acciones imprevistas y posibilidades impensadas. Por lo tanto, una tensión dinámica entre entendimientos previos y expectativas, y nuevas observaciones y experiencias se ponía en marcha con cada encuentro, y era modificada en la medida en que aquellos encuentros cambiaban con el tiempo (Schwartz 1994: 3).

A partir del análisis de la Histoire d'un voyage aux Isles Malouines (1770) del fraile benedictino Joseph Antoine Pernety, el presente trabajo se propone indagar entonces en torno al papel del relato de viaje en la construcción y reproducción de subjetividades, haciendo especial énfasis en la dimensión histórico-cultural de la colonización, las ambiciones de Francia en América y su desempeño en la carrera ultramarina en el transcurso del siglo XVIII. En este sentido, la relectura de un relato de viaje tal como la Histoire d'un voyage aux Îles Malouines y la consecuente restitución de su contexto de producción tienen por objetivo rastrear las distintas construcciones de una otredad cultural realizadas por el viajero en su papel de observador y cronista de viaje pero también en su función política de enviado especial de la Corona francesa ${ }^{3}$.

\section{La experiencia de Francia en América y su rivalidad con España. Impresiones de un benedictino al servicio de la Corona francesa}

El viaje realizado a las islas Malvinas entre 1763 y 1764 por el padre benedictino JosephAntoine Pernety debe comprenderse en el marco del proceso de expansión ultramarina que tuvo lugar entre fines del siglo XV y fines del siglo XVIII y cuyas consecuencias más relevantes fueron tanto la ampliación del mundo conocido por los europeos como la incorporación de nuevos territorios, identidades y poblaciones a la economía mundo (Besse 2003; Wallerstein 1984). En efecto, si en un primer momento de aquel proceso inicial de mundialización, en términos de Serge Gruzinski, fue la monarquía católica la primera en "unir las cuatro partes del mundo" (Gruzinski 2001: 90), la posterior participación de potencias ultramarinas como Inglaterra, las Provincias Unidas de los Países Bajos y Francia, sin duda dinamizaron aún más los intercambios, el tráfico comercial y la circulación de saberes entre las distintas partes del globo. En cuanto a las regiones geográficas bajo dominio 
europeo, Anthony Pagden ha resaltado la importancia de América como escenario principal de las disputas entre las distintas potencias advenedizas, así como la competencia existente entre ellas por el control político y comercial de este ámbito (Pagden 1997: 12). Por su parte, centrado en las repercusiones locales de la sujeción portuguesa y española en América y en las distintas formas en las que las potencias rivales disputaron ese dominio, Tulio Halperin Donghi (1985) ha destacado la primacía que en el siglo XVIII adquirieron los territorios americanos como teatro de operaciones de las rivalidades entre potencias ${ }^{4}$.

En el caso particular de Francia, merece ser señalado que su experiencia colonial en América en los siglos precedentes (y aún en el propio siglo XVIII) se encontró signada mayormente por el fracaso (Ferro 2009: 89). Esto se debió principalmente a la conjunción de dos aspectos determinantes que fueron, por un lado, la incorrecta implementación de una sucesión de políticas de ocupación de territorios estratégicos y, por el otro, el hecho de que toda empresa destinada a la conquista y a la expansión estuviese dirigida, organizada y financiada por la Corona. Aspecto que parece refrendar el propio editor de la Histoire d'un voyage aux Îles Malouines... al señalar que, más allá del impulso dado por los filósofos y de la acción de los propios marineros, toda empresa de colonización es en última instancia responsabilidad del monarca (Pernety 2012: 48 [1770a]). Acerca de este último punto, autores como Marc Ferro han llegado incluso a afirmar la existencia de un "doble fracaso colonial" al referirse a la política de Francia en América en los siglos XV y XVI y a la responsabilidad que cupo en ella a la propia Corona ${ }^{5}$. En sus términos:

La masa territorial francesa, con su fuerte monarquía y su nobleza poderosa, pero ajena al comercio, constituía una especie de polo negativo al oeste de Europa. (...) todos estos datos se sumanban para que la expansión colonial, en Francia, no pudiera ser más que voluntarista, emanando de la monarquía. Y esta, poco respaldada por la sociedad, no fue activa más que con sus propios medios, y en la medida en que luchaba por conservar su existencia en contra de la hegemonía española; o en que, católica, se enfrentaba a los ingleses protestantes (Ferro 2009: 69).
En función de este contexto, el análisis de la figura de Joseph-Antoine Pernety, acaso más conocida por haber participado vivamente del debate en torno a la naturaleza de América (Gerbi 1982), se presenta entonces como un medio eficaz para observar la forma en la que el espacio americano y las representaciones del otro fueron construidas por una Francia que, tras la firma del tratado de París en 1763 (a raíz de su derrota frente a Inglaterra en la guerra de los Siete Años) y la consecuente pérdida de sus territorios en Canadá, ambicionó incorporar a sus exiguos dominios nuevos territorios en ultramar ${ }^{6}$. Efectivamente, como han señalado Marc Ferro (2009:96) y Anthony Pagden (1997), a partir de 1763 finaliza lo que podría denominarse el primer imperio francés de ultramar, y con él las posibilidades concretas de ocupación territorial en América. En términos del segundo de estos autores:

Con la aplicación del Tratado de París del 10 de febrero de 1763 , que puso fin a la Guerra de los Siete Años, la presencia francesa en América quedó reducida a las islas del Caribe, las más importantes de las cuales eran, a efectos políticos y económicos, Guadalupe y Santo Domingo. Allí no había, como en Canadá, poblaciones indígenas con las que pudieran llegar a integrarse los colonizadores (Pagden 1997: 184).

El relato de viaje de Pernety, tan rico en observaciones relativas a la naturaleza de América, su flora, fauna y paisajes, bien podría leerse entonces desde el punto de vista político. En efecto, además de haber sido un insumo vital al enfrentarse al filósofo holandés Cornelius de Pauw en el debate en torno a la naturaleza de América, el viaje emprendido por Pernety a las islas Malvinas permite observar, en tanto "testimonio involuntario" (Bloch 1949: 25), la compleja trama de relaciones y vínculos de Francia, Portugal y España en territorios americanos.

En lo que refiere a la escritura y edición de la obra, resulta necesario señalar que tras haber participado como capellán de navío de la primera expedición francesa a las islas Malvinas (17631764), liderada por Louis-Antoine de Bougainville e inmediatamente anterior al primer viaje francés de circunnavegación emprendido dos años después por el mismo capitán ${ }^{7}$, Pernety publicó en 1769 un primer Journal historique d'un voyage fait aux Îles Malouines. El mismo fue adaptado a las exigencias 
del público general y publicado en París al año siguiente bajo el título completo de Histoire d'un voyage aux Îles Malouines fait en 1763 \& 1764; avec des observations sur le détroit de Magellan, et sur les Patagons, Par Dom Pernetty, Abbé de l'Abbaye de Burgel, Membre de l'Académie Royale des Sciences \& Belles Lettres de Prusse; Associé Correspondant de celle de Florence, \& Bibliothécaire de Sa Majesté le Roi de Prusse...

A su vez, en el marco de la disputa acerca de la naturaleza de América debe agregarse que aquel mismo año Pernety también dio a conocer su Dissertation sur l'Amérique et les Américains (1770), en la que apeló tanto a su propio testimonio como al de viajeros contemporáneos (como Amédée Frézier, el padre Feuillée, Antonio de Ulloa y Charles-Marie de La Condamine) para echar por tierra la hipótesis defendida por Cornelius de Pauw acerca de la naturaleza degradada de América.

\section{Ocupación y devolución de las islas Malvinas. Pernety, Bougainville y un nuevo intento de colonización francés en América}

En función de comprender más acabadamente el tenor de las observaciones y reflexiones realizadas por Joseph-Antoine Pernety en su viaje a las islas Malvinas, además de situar el relato de viaje del benedictino en su propio contexto de producción, recepción y circulación, también pareciera necesario indagar en torno a las motivaciones y objetivos detrás de la expedición en sí misma. Como lo indica su editor, el viaje emprendido en 1763 fue ordenado y financiado por la Corona francesa, la que desde el siglo XVI se había propuesto como objetivo la búsqueda y consecuente hallazgo de la Tierra Austral Incógnita, que era considerada en aquel entonces una tierra de abundancia y de clima templado ${ }^{8}$. En principio, fue el historiador hugonote Henri Lancelot-Voisin de la Popelinière quien, en la publicación de sus Trois Mondes (1582) a fines del siglo XVI, sugirió, ya que España y Portugal se habían instalado en el Nuevo Mundo, correspondía a Francia la ocupación de la Terra Australis. Dicha premisa sería retomada en los siglos siguientes por los distintos reyes de Francia y sus colaboradores (Pagden 1997: 89), llegando a su máxima expresión a mediados del siglo XVIII con la publicación de la Histoire des navigations aux Terres Australes (1756) de Charles de Brosses.
De allí que la Histoire d'un voyage aux Îles Malouines presente un extenso Discurso Preliminar, introducido por el propio editor de la obra de Pernety, en el que la expedición y ocupación de las islas Malvinas por parte de Francia se justifica en la medida en que las islas revisten una importancia estratégica para la posterior búsqueda del continente austral:

El relato de viaje, del que soy editor, es interesante y preciso y no conduce solamente al reconocimiento de las islas Malvinas, que encontramos habitadas solo por arañas de patas grandes y campanillas, y que la corte francesa acaba de ceder a la Corona de España. Es de una utilidad más general tanto para el Soberano como para todos los hombres pensantes por la facilidad que ofrece para acceder a las tierras australes y verificar lo que tantos viajeros han escrito sobre la existencia de esos gigantes del Polo llamados patagones (Pernety 2012: 32 [1770a]) .

Ahora bien, al margen de que la Corona francesa se haya propuesto dar con aquella Quinta Pars, la ocupación de las islas Malvinas debía justificarse primero en términos jurídicos, porque, como Francia bien sabía, aquellas islas eran nominalmente posesión española. Como ha indicado Anthony Pagden, los franceses apelaron entonces al argumento del derecho romano conocido como Res Nullius, este sostenía que “todas las 'cosas vacías', entre las que se incluían las tierras no ocupadas, eran propiedad común de toda la humanidad mientras no se les diera algún uso, normalmente agrícola. La primera persona que utilizara de este modo la tierra pasaba a ser su propietario" (Pagden 1997: 103). De allí que en la Histoire d'un voyage aux Îles Malouines el editor haga especial hincapié en el hecho de que los primeros en descubrirlas fueron los navíos provenientes de Saint-Maló a principios del siglo XVIII (Pernety 2012: 34 [1770a]).

Estas justificaciones resultaron, sin embargo, infructuosas. A poco de haber instalado un contingente de colonos en las islas, Francia debió reconocer la posesión española de las mismas y estas debieron ser devueltas a España. El segundo viaje a las islas Malvinas emprendido por Louis-Antoine de Bougainville, ya sin la presencia de Pernety, se produce entonces en 1766 con el objetivo primero 
de levantar el asentamiento allí emplazado. Tras haber realizado esto último, Bougainville emprenderá desde allí el primer viaje de circunnavegación francés jamás realizado, acaso la agenda secreta de aquel segundo viaje a las mencionadas islas (Bougainville 1771).

\section{El imperio español y portugués ante los ojos de un francés en el marco de las reformas borbónicas y pombalinas}

En el transcurso de su viaje a las islas Malvinas, la expedición de la que participa Pernety hace recalada en distintos puertos del imperio portugués y español en América primero, y luego en tierras patagónicas. En efecto, los navíos de Bougainville -Guyot du Clos (a cargo de la fragata Aigle) y Chenart de la Giraudais (capitán de la corbeta Sphinx)- parten hacia las islas Malvinas desde Saint-Malo, Francia, el 8 de septiembre de 1763 con una tripulación de más de 140 hombres y una capacidad bélica de más de 28 cañones, para llegar a América dos meses y medio más tarde. Los franceses avistan las costas de Brasil hacia fines de noviembre, cuando atracan en el canal circundante a la isla de Santa Catalina, en el actual estado del mismo nombre.

La expedición permanece allí alrededor de un mes y luego continúa su viaje hacia el sur, para llegar al Río de la Plata el 22 de diciembre del mismo año. Reconoce la isla de Lobos, fondea cerca de la isla de Maldonado y llega algunos días más tarde y tras intensas tormentas al puerto de Montevideo. Los viajeros vuelven a zarpar a mediados de enero y llegan finalmente a las islas Malvinas el 2 de febrero de 1764. Asentados en las islas, emprenden en el transcurso de su estadía algunos viajes al estrecho de Magallanes, donde encuentran poblaciones de indígenas, que son descritas en un apartado agregado al viaje de Pernety y cuyo título es "Observaciones sobre el Estrecho de Magallanes y los Patagones". En el Capítulo III de ese mismo apartado también puede hallarse la descripción de un viaje posterior al mencionado estrecho, realizado en 1766 , por los señores Duclos-Guyot y de la Giraudais ${ }^{10}$. En cuanto a las islas Malvinas, tras permanecer allí varios meses, a excepción de los colonos que permanecerán en las mismas, el resto de la tripulación regresará al puerto de Saint-Malo el 26 de junio de aquel mismo año.

Los distintos puertos y ciudades que los franceses recorren a lo largo del viaje permiten a Pernety observar entonces las costumbres de un amplio espectro de poblaciones, entre las que pueden contarse aquellas de los portugueses y españoles en Santa Catalina y Montevideo, respectivamente, las de los brasileños en el área circundante a la isla de Santa Catalina, las de los "salvajes" y jesuitas del Paraguay y también las de los patagones en la América austral. En lo que refiere específicamente a estos últimos, debe señalarse que si bien sus costumbres no son descritas por el propio Pernety, sí son incluidas por este en el ya mencionado apartado acerca de los patagones en el estrecho de Magallanes.

Dentro de este conjunto de identidades, construidas por Pernety a partir de su experiencia en América, pero también a base de sus propios postulados e ideas, merecen particular atención las diferencias que el propio benedictino establece entre las sociedades que observa. Las mismas, sugiere el viajero, están determinadas por las leyes y el clima de los países que cada pueblo habita:

Las leyes de los países determinan las costumbres de quienes los habitan, es por eso que las costumbres de las naciones son tan distintas entre ellas. Y dado que el clima también influye mucho, una determinada ley justa en Noruega, no lo será en Guinea. Los conocimientos adquiridos en los pueblos que llamamos civilizados también han sido la inspiración de leyes desconocidas entre aquellos a los que se nos ocurrió llamar salvajes (Pernety 2012: 143 [1770a]).

Respecto de la influencia del clima, es posible que Pernety haya tenido acceso a los escritos de Jean Bodin en torno a la determinación de las distintas zonas climáticas del globo respecto de las cualidades físicas, fisiológicas, morales y políticas de cada pueblo ${ }^{11}$. A partir de su traducción al francés en 1567, los principios expresados por Bodin en Le Théâtre de la Nature Universelle, auquel on peut contempler les causes efficientes et finales de toutes choses, desquelles l'ordre est continué par questions et responses fueron aplicados pronto a América (Lestringant 1982: 221), dando lugar, con frecuencia, a lecturas tergiversadas o intencionalmente orientadas según los propósitos de cada nación. Ya en el siglo XVIII los supuestos de Bodin $\mathrm{y}$, en términos generales, la teoría de la influencia de las zonas climáticas fueron incorporados por naturalistas como Georges-Louis Leclerc, Conde 
de Buffon, en su Histoire Naturelle (1749-1788), o filósofos como el Barón de Montesquieu en su De l'esprit des Loix (1748) (Urteaga 1993). En el caso particular de Pernety, la influencia del clima es considerada un factor de influencia en la conducta de los distintos pobladores de América ${ }^{12}$, aunque en ciertas ocasiones el autor describa las características de un pueblo que, en su opinión, se comporta de la forma en que lo hace "a pesar del clima"13.

En cuanto a los distintos pueblos hallados en el transcurso de su viaje, los brasileños son caracterizados en principio como gente muy hospitalaria. En efecto, a poco de fondear en las proximidades de la isla de Santa Catalina, Pernety narra cómo los habitantes de la costa se acercan al barco para ofrecer a los franceses frutas frescas, acción que les es prohibida por las autoridades portuguesas deseosas de impedir cualquier trato entre los franceses y los habitantes locales (Pernety 2012: 96 [1770a]). En el Capítulo VI, acerca de las costumbres y usos de los brasileños, Pernety vuelve a hacer hincapié en la hospitalidad de los mismos al señalar que: "erróneamente se considera a los brasileños, que solo se muestran crueles con sus enemigos declarados, como los hombres menos civilizados del Nuevo Mundo". Seguidamente destaca que, salvo un reducido número de ellos, "la mayoría de los brasileños son muy humanos, especialmente con los extranjeros, a los que reciben con mucha deferencia" (Pernety 2012: 144 [1770a]). En esta instancia, el benedictino remite a la experiencia del pastor hugonote Jean de Léry, quien había convivido entre las poblaciones tupi-guaraníes tras ser expulsado por el vicealmirante Nicolás Durand de Villegaignon de la primera colonia francesa implantada en el actual Rio de Janeiro entre 1555 y 1558 (Pernety 2012: 145-6 [1770a]).

En efecto, en su Histoire d'un voyage faict en la Terre du Brésil (1578) Léry había hecho hincapié en lo bien que había sido recibido por las poblaciones tupíes tras su expulsión del Fuerte de Coligny en la Bahía de Guanabara, episodio que alimentaría el topos de la hospitalidad desarrollado luego, y con aún más fuerza, por Michel de Montaigne en su célebre ensayo Sobre los Caníbales (1580). Pernety pareciera nutrirse del relato de viaje de Léry en los párrafos siguientes a la primera mención que realiza del hugonote, cuando describe las costumbres de los brasileños y, al igual que había hecho Léry en 1578, señala por último que los hombres "llamados bárbaros a causa de la crueldad con la que tratan a sus enemigos, solo son antropófagos a los ojos de los más jurados de ellos" (Pernety 2012: 146 $[1770 \mathrm{a}])^{14}$.

Acerca de los mulatos y los esclavos hallados en la ciudad, Pernety dedica algunas líneas a describir su aspecto físico y las ropas con las que suelen vestirse. A poco de recorrer la isla de Santa Catalina, el viajero señala que los mulatos, que considera son los más numerosos en ambos sexos en toda la isla, son "el resultado de una mezcla de brasileños con mujeres negras", de "cara fea y aspecto salvaje" (Pernety 2012: 99 [1770a]). Los esclavos, por su parte, "están casi desnudos" y realizan el trabajo que los portugueses prefieren no hacer: "En general, tanto hombres como mujeres viven en un gran ocio, dejando a los esclavos las tareas de la casa y otros trabajos..." (Pernety 2012: 100-101 [1770a]).

En lo que refiere a "sus amos", Pernety considera a los portugueses hombres celosos, desconfiados y ociosos. En efecto, tras realizarse una recepción en honor a los franceses organizada por el gobernador de Santa Catalina y los oficiales de la guarnición, Pernety explica que los platos ofrecidos "no eran demasiado ricos para nuestro paladar francés", que el pan le ha parecido simplemente malo y que la vajilla con la que todo fue servido era directamente anticuada (Pernety 2012: 98 [1770a]) . Esto no impide, sin embargo, que entre los representantes de las respectivas coronas se realice "la entrega mutua de regalos" y que el gobernador, por su parte, autorice a la comitiva francesa a abastecerse de todo cuanto necesita (agua, leña, frutas, etc.) para emprender su viaje a las islas Malvinas (Pernety 2012: 104 [1770a]).

Merecen un comentario aparte los españoles de Montevideo, a quienes Pernety dedica la totalidad del Capítulo X, que lleva por título "Sobre las leyes, costumbres y hábitos de Montevideo". En la opinión del viajero, a excepción de los comerciantes y un pequeño número de artesanos, los españoles de aquella colonia nueva "son muy ociosos, solo ocupan su tiempo en tomar mate, conversar y fumar cigarros" (Pernety 2012: 172 [1770a]). Tras describir sus vestimentas (dentro de las que incluye el poncho y sus beneficios), y el comportamiento de las mujeres en reuniones sociales, Pernety vuelve a remarcar su indolencia al describir las danzas que practican ${ }^{15}$. Respecto del gobernador y los militares que lo acompañan, también ellos "llevan una vida ociosa”, aspecto que Pernety no deja de señalar a 
lo largo del capítulo. Su descripción de un día en la vida de un español en Montevideo resulta, en este sentido, por demás elocuente de sus impresiones acerca de los españoles en la América meridional:

El estilo de vida de los españoles es muy simple. Los hombres que no trabajan en el comercio se levantan muy tarde, al igual que las mujeres, y después se quedan de brazos cruzados hasta que se les ocurra ir a fumar un cigarro con su vecino. A menudo se los ve en grupos de cuatro o cinco, frente a alguna casa, fumando y charlando. [...] Se pueden quedar así dos horas, sin hablar de nada en particular, fumando y tomando mate. [...] Tocan la guitarra u otro instrumento y cantan, y toman mate mientras las negras se ocupan de la comida. [...] Después del almuerzo, los señores y sus esclavos hacen lo que llaman la siesta, o sea que se desvisten, se acuestan y duermen dos o tres horas. Los obreros, que viven solo del trabajo de sus manos, también se toman esas horas de descanso. Esta pérdida de una buena parte de la jornada de trabajo es la causa de que se hagan tan pocas cosas... (Pernety 2012: $177-8$ [1770a])

Durante su estadía en Montevideo, el benedictino también entra en contacto con un grupo de indios provenientes del Paraguay (pero que en realidad ubica a seis o siete leguas de Montevideo). Pernety señala que no están acostumbrados a comerciar y desconocen el valor del dinero, que intercambian por pieles sin tener conciencia de la desproporción entre el valor de uno y otro objeto. También describe la forma en la que se visten, los aceites que se untan y el hecho de que no utilizan calzado. Respecto de su contextura física, hace especial hincapié en el hecho de que están bien proporcionados y formados ${ }^{16}$; y en relación con sus actividades, el benedictino resalta en todo momento lo hábiles y prácticos que pueden llegar a ser. $\mathrm{Al}$ igual que con los "salvajes" encontrados en Santa Catalina, la descripción de los indios hallados en Montevideo es por demás positiva, hecho que se refuerza cuando al final del capítulo concerniente a "los indios del Paraguay" Pernety critica el despotismo de los jesuitas y llama al estudio de estas poblaciones por parte de políticos y filósofos:
Es lamentable que solo conozcamos a esos indios a través de los jesuitas o de los partidarios de su despotismo. Para el político, su estudio sería tan interesante como el de los españoles, y para el filósofo aun más, porque están más cerca de la naturaleza (Pernety 2012: 189 [1770a]).

Una apreciación muy similar, aunque esta vez relativo a los patagones, puede constatarse en los escritos de Guyot, incluidos en la edición del viaje de Pernety de 1770. En efecto, es el mismo Guyot quien al narrar su encuentro con estas poblaciones en su viaje al estrecho de Magallanes explica: "Estos hombres son parecidos a los indios de Montevideo..." (Pernety 2012: 301 [1770a]). Por su parte, el relato de Duclos muestra un encuentro (posterior presumiblemente) de muchas más aristas, donde las relaciones entre patagones y franceses son cordiales pero no al punto en el que son relatadas por Guyot. En cuanto a las descripciones de los indios realizadas por Pernety, si han de compararse con sus observaciones de los portugueses y españoles de Santa Catalina y Montevideo, la habilidad y hospitalidad de los primeros frente a la pereza y desconfianza de los segundos se presenta como una diferencia fundamental en la construcción de identidades que el benedictino realiza en su viaje a las islas Malvinas.

En la misma línea, su opinión de los jesuitas, recientemente expulsados de América por la Corona de Portugal, se encuentra visiblemente afectada por tales acontecimientos. En efecto, la expulsión de la Compañía de Jesús de todos los dominios portugueses se produce en 1759, cuando, según ha señalado Tulio Halperín Donghi, "la Compañía fue tenida, no totalmente sin fundamento, por responsable de la resistencia que la rectificación de fronteras americanas entre España y Portugal, decidida en 1750, encontró entre los indígenas de sus misiones orientales del Uruguay" (Halperin Donghi 1985: 31). El episodio es narrado por Pernety en el Capítulo VIII, cuando se produce el encuentro entre Bougainville y su comitiva y el gobernador de Montevideo don José Joaquín de Viana, encargado en aquel entonces de ir contra los jesuitas. Adoptando una postura favorable al accionar de Viana contra el levantamiento jesuita, Pernety explica que algunos años antes el gobernador:

[había sido] encargado por el rey de

España de comandar las tropas enviadas 
al Paraguay contra los indios que, según se dice, se sublevaron instigados por los jesuitas, que en estas regiones actúan como déspotas y se niegan a someterse a los acuerdos establecidos entre las Cortes de España y Portugal para fijar los límites de sus respectivos dominios (Pernety 2012: 157 [1770a]).

El viaje de Pernety se inscribe entonces dentro del proceso de hostigamiento a la Compañía de Jesús que solo finalizaría con la disolución de la misma en 1773. En el caso de España, los jesuitas serían expulsados de América en 1767 a instancias del Conde de Campomanes. Algunos años antes, en 1762, habían sido expulsados de Francia por el Duque de Choisieul, ministro de Marina bajo el reinado de Luis XV y quien coincidentemente convoca a Pernety a participar en calidad de capellán del viaje organizado por Bougainville al año siguiente a las islas Malvinas (Pernety 2012: 61 [1770a]). Es por ello que, durante su estancia en Montevideo, el benedictino dice recibir rumores de que ciertos jesuitas en Buenos Aires habían estado difamando al rey de Francia por su reciente expulsión de aquella nación (Pernety 2012: 160-1 [1770a]).

En función de las miradas y de los criterios utilizados por Pernety para dar cuenta de los otros que describe, es posible afirmar entonces que el benedictino arriba a dos ciudades que dan cuenta de los cambios y de la intensificación de tendencias que en los últimos 15 años habían atravesado tanto los distintos virreinatos de la América hispana como el Brasil de las reformas pombalinas. En efecto, como ha señalado Tulio Halperin Donghi, el intento de imponer una administración mejor organizada y centralizada acentuó la fragmentación interna de la sociedad hispanoamericana (Halperin Donghi 1985: 73). Pernety observa entonces una sociedad en transición, diferencia los usos y costumbres de unos y otros y, en calidad de representante de la Corona francesa, realiza sus propias proyecciones respecto de los pueblos y tierras que encuentra a su paso. $\mathrm{Al}$ respecto, no debe olvidarse que en esta segunda fase de expansión transoceánica el discurso de la Leyenda Negra fue utilizado y dirigido por Francia e Inglaterra en contra de las potencias de la fase anterior, España y Portugal (Ette 2014: 41). Coincidentemente, mientras Pernety considera a los portugueses y españoles en América ociosos, describe a los "salvajes" como hábiles, dinámicos, lúcidos.
En cuanto a las tierras visitadas, de ser trabajadas por alguna otra nación (acaso Francia) estas serían aún más productivas de lo que son actualmente.

\section{Consideraciones finales}

El análisis del viaje de Joseph-Antoine Pernety a las islas Malvinas ha permitido observar las múltiples formas en las que, hacia fines del siglo XVIII, la construcción del espacio americano ocupó un lugar privilegiado en la literatura de viaje. Asimismo, el hecho de que Pernety haya sido oficialmente designado por la Corona francesa para no solamente actuar como capellán sino también redactar el diario de abordo (Freijomil 2005: 35), permite a su vez aseverar que en esta segunda etapa del período de expansión ultramarina las representaciones del otro americano, pero también del otro español, estuvieron muchas veces condicionadas por intereses políticos al tiempo que también fueron utilizadas en función de los proyectos expansionistas de las potencias ultramarinas rivales (Paredes 2013). En efecto, en un período en el que la presencia de españoles y portugueses en América ya estaba consolidada, los hábitos y costumbres adoptados por peninsulares y criollos resultan lo suficientemente diferentes como para que Pernety los considere dignos de describir. En este sentido, merece ser señalado que las prácticas de los europeos en América son descritas por el benedictino como necesariamente distintas de las prácticas francesas, españolas y portuguesas mantenidas en el continente europeo.

La diferenciación y delimitación de un comportamiento propio de los "españoles en Montevideo" o de los "portugueses en Santa Catalina", los convierte de esta forma en otros tipos de alteridad americana, que al igual que los mulatos, los patagones y los "salvajes" encontrados en tierras bajo dominio portugués y español, conforman un conjunto de otredades que, desde la perspectiva de un monje benedictino al servicio de la Corona francesa, completan el cuadro o mapa de identidades propias de América.

Respecto de la diferenciación que el benedictino realiza entre los españoles y portugueses americanos y sus correligionarios europeos, es probable que el hecho de que el viaje de Pernety a América se produjera en el contexto de las Reformas Borbónicas haya exacerbado los antagonismos entre europeos y criollos, percibidos por Pernety en su viaje por América del Sur y divulgados rápidamente en Francia 
y en Europa a partir de la publicación de su Journal en 1769 , pero sobre todo de la publicación de su más completa Histoire d'un voyage... en 1770 y su versión inglesa, History of a voyage to the Malouine (or Falkland) Islands, de 1771.

Pero si tal como hemos dicho el viaje es constructor de nuevas identidades, debe ser señalado además que en el transcurso del viaje a las islas Malvinas y en los años que siguieron a la primera publicación del relato, la figura de Pernety también se hizo acreedora de una nueva identidad. En efecto, el benedictino interviene en el debate acerca de la naturaleza de América en calidad de "testigo" de aquello que ha "visto con sus propios ojos" en América. La experiencia del viaje a las islas Malvinas ha operado entonces como constructora de la propia identidad del viajero, que adquiere autoridad frente a sus pares en la medida en que puede dar cuenta de aquello de lo que ha sido testigo y separarse de esta manera de la opinión del filósofo o del geógrafo de gabinete, que el benedictino asocia con la figura de Cornelius de Pauw (Martínez 2011).

Así, en su Dissertation sur l'Amérique et les Américains (1770) Pernety contrapone el valor de "lo visto" a las inferencias realizadas por De Pauw, haciendo especial énfasis en la falta de conocimiento "real" que el filósofo holandés tiene de América y en la validez de su propio testimonio como viajero a aquellas tierras (Ette 2014: 42-3). "Reconocí que M. de P. [...] sabe poco de América y de lo que ella contiene", expresa Pernety en el Prefacio de la obra mencionada para poco después ofrecer como garantía de sus propios postulados el hecho de que él mismo ha viajado a las tierras que describe: "he visto con mis propios ojos la mayoría de las cosas que son relatadas" (Pernety 1770b: 4) [Traducido por la autora]. Algunas páginas más adelante enfatiza aún más el supuesto error en el que De Pauw ha caído al hablar con autoridad acerca de algo que en realidad jamás ha visto: "Si M. de P. hubiese viajado a América y la hubiese recorrido en persona, la hubiera conceptuado y observado verdaderamente con otros ojos", establece sentenciosamente Pernety (Pernety 1770b: 12) [Traducido por la autora].

Esta última observación pareciera confirmar que el análisis de las observaciones de Joseph-Antoine Pernety y el estudio de la literatura de viaje en su función de productora de subjetividades e identidades (propias y ajenas), resultan herramientas sutiles pero a la vez sustantivas a la hora de complicar las diferentes lecturas que se han realizado en torno a la "colonización" y a su impacto respecto de los propios protagonistas del proceso de expansión ultramarina que tuvo lugar en la llamada primera modernidad.

\section{Referencias Citadas}

Besse, J.-M.

2003 Les Grandeurs de la Terre. Aspects du savoir Géographique à la Renaissance. ENS Éditions, Lyon.

Bloch, M.

1949 Apologie pour l'Histoire ou métier d'Historien. Armand Colin, París.

Bougainville, L.A.

1771 Voyage autour du monde par la Frégate du roi "la Boudeuse" et la flûte "l'Étoile"; en 1766, 1767, 1768 \& 1769 par Louis Antoine de Bougainville. Saillant \& Nyon, París.

Cañizares-Esguerra, J.

2007 Cómo Escribir la Historia del Nuevo Mundo. Fondo de Cultura Económica, Buenos Aires.

De Certeau, M.

1975 L'écriture de l'Histoire. Gallimard, París.

Ette, O.

2014 Palabras-Dominios-Genealogías. Cornelius de Pauw y la Disputa por un Mundo Nuevo. Telar. Revista del Instituto Interdisciplinario de Estudios Latinoamericanos, 11-12 (2013-2014). Facultad de Filosofía y Letras, Universidad Nacional de Tucumán, San Miguel de Tucumán.

Ferro, M.

2009 La Colonización. Una Historia Global. Siglo XXI, México.
Freijomil, A.

2005 Estudio Preliminar, Traducción y Notas. En Viaje Alrededor del mundo a bordo de la Fragata real La Boudeuse y la urca Étoile, en 1766, 1767, 1768 y 1769, L. A. de Bougainville. EUdeBA, Buenos Aires.

Gerbi, A.

1982 La Disputa del Nuevo Mundo. Historia de una Polémica, 1750-1900. Fondo de Cultura Económica, México.

Gruzinski, S.

2001 Les mondes mêlés de la Monarchie Catholique et autres 'Connected Histories'. Annales. Histoire, Sciences Sociales $56, \mathrm{~N}^{\circ} 1: 85-117$.

Halperin Donghi, T.

1985 Reforma y Disolución de los Imperios Ibéricos, 17501850. Alianza Editorial, Madrid.

Hartog, F.

2002 El Espejo de Heródoto. Ensayo sobre la Representación del otro. Fondo de Cultura Económica, Buenos Aires.

Lancelot-Voisin de la Popelinière, $\mathrm{H}$. 1582 Les Trois Mondes. P. L'Huillier, París.

Lestringant, F.

1982 Europe et Théorie des climats dans la Seconde Moitié du XVIe siècle. En La Conscience Européenne au XVe et au XVIe siècle, AA.VV., pp. 206-226. École Normale Supérieure de Jeunes Filles, París. 
Martínez, C.

2011 En torno a la Idea de Naturaleza en el siglo XVIII y el Impacto que el Descubrimiento del Nuevo Mundo ejerció sobre ella. En Dominio y reflexión. Viajes reales y viajes imaginarios en la Europa moderna temprana (siglos XV a XVIII), M. J. Gandini, M. López Palmero, C. Martínez, R. C. Paredes, pp. 187-214. Editorial de la Facultad de Filosofía y Letras de la Universidad de Buenos Aires, Buenos Aires.

Martínez, C.

2013 Tras las Huellas de una Singular Experiencia Colonial: la Francia Antártica en los Orígenes de la Modernidad Temprana Europea. En Fragmentos Imperiales. Textos e imágenes de los imperios coloniales en América (Siglos XVI-XVIII), M. J. Gandini, M. López Palmero, C. Martínez, R.C. Paredes, pp. 61-63. Editorial Biblos, Buenos Aires.

Pagden, A.

1997 Señores de todo el mundo. Ideologías del Imperio en España, Inglaterra y Francia (en los siglos XVI, XVII y XVIII). Editorial Península, Barcelona.

Paredes, R.C.

2013 Aliados Alarmantes, los Aventureros Ingleses y la Visión del Indígena Americano (siglos XVI y XVIII). En Boletín AFEHC 56 (27 de junio de 2013): http://afehc-historiacentroamericana.org/index.php?action=fi_aff \&id $=3454$ (20 de octubre de 2014).

Pernety, J.-A. (Dom).

1770a Histoire d'un Voyage aux isles Malouines, fait en 1763 \& 1764; avec des Observations sur le détroit de Magellan, et sur les Patagons, Par Dom Pernetty, Abbé de l'Abbaye de Burgel, Membre de l'Académie Royale des Sciences \& Belles Lettres de Prusse; Associé Correspondant de celle de Florence, \& Bibliothécaire de Sa Majesté le Roi de Prusse. Saillant \& Nyon, Delalain, París.

Pernety, J.-A. (Dom).

1770b Dissertation sur l'Amérique et les Américains contre les Recherches Philosophiques de M. de P***. S. ed., Berlin.

Pernety, J.-A. (Dom).

2012 [1770a] Historia de un Viaje a las Islas Malvinas. Eudeba, Colección Reservada del Museo del Fin del Mundo, Buenos Aires.

Schwartz, S. B. (Ed.).

1994 Implicit Understandings: Observing, Reporting and Reflecting on the Encounters between Europeans and other peoples in the early modern era. Cambridge University Press, Cambridge.

Urteaga, Luis.

1993 La Teoría de los climas y los Orígenes del Ambientalismo. En Cuadernos críticos de geografía humana, (noviembre de 1993), Universidad de Barcelona, Año XVIII, Número 99: http://www.ub.edu/geocrit/geo99.htm (5 de noviembre de 2014).

Wallerstein, I.

1984 El Moderno Sistema Mundial II. El Mercantilismo y la Consolidación de la Economía-Mundo Europea, 16001750. Siglo XXI, México.

Notas

1 "En 1556, Jean de Léry tiene veinticuatro años. Su Historia, veinte años más tarde, cambia en forma circular el movimiento de partida que iba de par-deçà (aquí, Francia) a par-delà (allí, los Tupis). Mueve el viaje en un ciclo. Trae de allí un objeto literario, el salvaje, que le permite regresar al punto de partida. El relato produce el regreso del sí al mismo por medio de la mediación del otro". (De Certeau 1975: 250) [traducción de la autora]

2 En términos de Anthony Pagden (1997: 12), "el descubrimiento por parte de los pueblos de Europa de que entre su continente y Asia existía otro del que no tenían conocimiento, ni constancia de contacto alguno antes de 1492, ha sido descrito como un acontecimiento de alcance histórico mundial casi desde el día en que Colón regresó de su primer viaje. Aquello representó, según lo formuló David Hume en 1757, 'el comienzo real de la historia moderna"'.

3 Perenty explica: "cuando estaba a punto de partir recibí las órdenes del rey, por una carta del señor duque de Choiseul, ministro de la marina, de embarcarme en él; tal elección no podía más que halagarme y tomé con prontitud esta ocasión de ser útil a mi patria" (2012:61 [1770a]).

4 Para este autor: “...la ya evocada transformación del sistema europeo en mundial acrece la significación de las regiones no europeas, a la vez como botín y como teatro de las rivalidades entre potencias. Los capítulos americanos de las guerras europeas se hacen cada vez más significativos; a fines del siglo XVIII resulta ya incomprensible que a principios de la misma centuria las Indias españolas hayan asistido solo como remotas espectadoras a esa vasta guerra europea que fue la de sucesión de España" (Halperin Donghi 1985: 18).

5 Esto se debió en gran parte a que en el siglo XV sus marineros no participan en los grandes descubrimientos; y "en el XVI, porque está también ausente de la conquista de las bases navales, de las rutas de las grandes ganancias que se llevan a cabo en Asia o en América" (Ferro 2009:69).

6 "El señor de Bougainville, caballero de Saint Louis y coronel de infantería, se propuso compensar a Francia de esa pérdida con el descubrimiento de las tierras australes y de las islas que encontraran en el camino" (Pernety 2012:61 [1770a]).

7 Al regreso de su viaje Pernety dejó los hábitos y, bajo la protección de Federico II se convirtió en su bibliotecario al tiempo que en encargado de la abadía de Bürgel en Turingia (Gerbi 1982: 105).

8 La misma es definida por el editor en su discurso preliminar como "vastas regiones situadas más allá de los extremos meridionales del mundo conocido y cuya extensión ha sido calculada en ocho millones de leguas cuadradas, que forman un contrapeso enorme en el equilibrio del globo" (Pernety 2012: 31 [1770a]). Véase también la página 43. Acerca de la temperatura en aquellas latitudes, tras permanecer en las islas Malvinas algunos meses el mismo Pernety se referirá al clima templado de las mismas.

$9 \quad$ El propio Pernety establece que el hallazgo de la Tierra Austral y de cualquier isla hallada en su camino compensaría la pérdida del Canadá en manos de los ingleses. Véase para ello la página 61. 
10 Este viaje fue realizado en el marco de la segunda expedición de Louis-Antoine de Bougainville a los mares del sur, que terminó por convertirse en el primer viaje de circunnavegación jamás emprendido por la Corona francesa.

$11 \quad$ Al respecto Lestringant ha señalado: "Heredado de la medicina y de la filosofía griegas, conocido durante la Edad Media, favorable en la época del primer humanismo occidental, el principio del determinismo mesológico encuentra en la segunda mitad del siglo XVI, específicamente en Francia, una suerte sin precedente. Permite entonces, a partir de la elaboración sistemática de Jean Bodin, establecer una grilla coherente y global de interpretación del universo al tiempo que deviene la base de las ciencias políticas modernas" (Lestringant 1982: 206). [Traducción de la autora]

12 "El aire es malsano, los hombres están, a pesar de ellos, en un singular estado de inercia y la única actividad de la naturaleza es devorar a sus habitantes" (Pernety 2012: 108 [1770a]).
13 "Las portuguesas que se establecieron o que nacieron en la isla de Santa Catalina o en las costas del continente que visitamos son de piel muy blanca a pesar del clima" (Pernety 2012: 100 [1770a]).

14 Acerca de la opinión de Léry respecto de la crueldad y el grado de hospitalidad de las poblaciones tupi-guaraníes véase Martínez (2013).

15 A excepción de un baile llamado "calenda" que bailan tanto negros como mulatos y blancos y que Pernety considera lascivo y obsceno. El mismo fue incorporado a las colonias americanas a raíz de la importación de esclavos.

16 "Los que yo vi eran bien proporcionados, estaban bien erguidos, con los brazos y piernas bien formados [...] Las mujeres, igual que los hombres, tenían un aspecto despierto, la cara redonda pero sin ser gorda, ojos muy grandes llenos de fuego..." (Pernety 2012: 187 [1770a]). 
